\title{
SINDICATO Y COMUNIDAD INDUSTRIAL *
}

Aunque legal y prácticamente, el Sindicato y la Comunidad Industrial constituyen dos instituciones diferentes, con personeria jurídica distinta y finalidades propias, la relación entre ambas resulta obvia. $Y$ es que Sindicato y Comunidad Industrial son instituciones representativas de la colectividad de trabajadores. Por ello, conviene señalar con precisión las razones de su distinción, la forma como la ley consagra un estatuto diferente para cada una de ellas y los campos en que inevitablemente deben relacionarse para el mejor cumplimiento de su función en defensa y beneficio del trabajador.

Por razones de metodología vamos a partir de las distinciones para concluir en las relaciones, con una advertencia previa: cuando se habla de Sindicato se hace referencia al sindicato de empresa exclusivamente.

\section{ORIGEN:}

\subsection{Constitución voluntaria en el Sindicato.}

Conforme al principio de libertad sindical consagrado por el Convenio de la Organización Internacional del Trabajo No 87, aprobado por el Congreso del Perú mediante Resolución Legislativa No 13281, de 15 de diciembre de 1959, y su reglamentación promulgada mediante Decreto Supremo No 009 de 3 de mayo de 1961, existen sindicatos únicamente en aquellos centros de trabajo en los que así lo haya dispuesto la mayoría de trabajadores.

* Este trabajo forma parte de un manual que sobre comunidades industriales va a publicar DESCO (Centro de Estudios y Promoción del Desarrollo). Se incluye en este volumen con autorización de esa institución, por lo cual le expresamos nuestro agradecimiento.
Precisamente por la libertad de sindicalización, los tres primeros artículos del Decreto Supremo citado disponen el compromiso del Estado de garantizar la libre asociación de los trabajadores, la prohibición de los empleadores de realizar actos que tiendan a coactar o restringir, en cualquier forma, el derecho de libre asociación profesional, y la obligación de la Autoridad de Trabajo de evitar cualquier intervención que tienda a limitar la libre constitución de sindicatos.

De tal manera que si la mayoria trabajadora decide organizar su asociación profesional, y cumple con los requisitos legales, ésta quedará válidamente constituida. En tanto que si la mayoría escoge no tener sindicato, no existe ninguna disposición legal que los obligue a tenerlo.

Sin embargo, desde que el Sindicato, por esencia, va a representar a la colectividad de trabajadores, las normas que regulan el derecho de asociación profesional consagran ciertos requisitos para la validez de la constitución de un sindicato y para preservar el principio de la unidad de sindicalización que aunque no está expresamente declarado en la legislación está establecido en los requisitos constitutivos y está aceptado por la jurisprudencia administrativa.

Asi, para constituir un Sindicato se requiere que el $50 \%$ de los trabajadores suscriban el acta de constitución $\mathrm{y}$, al mismo tiempo, se requiere que los suscriptores sean cuando menos 20 miembros (arts. $11 \mathrm{y}$ 7 del D.S. de 3 de mayo de 1961).

Conviene, además, aclarar que en el Perú aún subsiste la diferencia de trabajadores por categorias, existiendo por ello sindicatos de empleados, sindicatos de obreros y sindicatos únicos. 
Resulta, entonces, que pueden constituirse organizaciones sindicales únicamente o exclusivamente para obreros. En estos casos, los requisitos de mayoría serán cumplidos por el $50 \%$ de los servidores de la misma categoría. Además, las asociaciones profesionales de una sola categoría represenian solamente a la colectividad de trabajadores a la que corresponde: Sindicato de Empleados a empleados y Sindicatos de Obreros a obreros, exclusivamente.

No es así con los sindicatos únicos que representan a toda la colectividad de trabajadores del centro de trabajo. De otro lado el requisito de mayoria debe ser cumplido por cada una de las categorias de trabajadores por separado (art. 20 de la Resolución Ministerial de 23 de febrero de 1960).

Se concluye, pues, que solamente en los centros de trabajo en los que la mayoría haya decidido la constitución de sindicatos éstos tienen existencia legal. La constitución o formación de sindicatos depende de la voluntad de los trabajadores.

\subsection{Constitución por mandato de la ley en la Comu- nidad Industrial.}

Las Comunidades Industriales, que también representan a la colectividad de trabajadores, han tenido un origen distinto. Nacieron por mandato expreso del Art. 23 del Decreto Ley 18350 en toda empresa industrial y están integradas por el conjunto de trabajadores estables que laboran a tiempo completo.

Más aún, el Art. 8ㅇ del Decreto Ley 18384 dispuso especííicamente que en caso de que la comunidad industrial no se hubiese instalado dentro del plazo señalado, el Ministerio de Industria y Comercio procederá a instalarla de oficio, a pedido de cualquier trabajador.

No es pues la voluntad de uno o varios trabajadores to que determina la constitución de una comunidad industrial.

No obstante, la misma ley señala algunos requisitos para que en una empresa industrial tenga aplicación su mandato. Existe entonces Comunidad en aqueIla empresa industrial que tenga seis o más trabajadores o que, teniendo menos de seis trabajadores, su ingreso bruto anual sea superior a un millón de soles.

Por tener la Comunidad Industrial su origen en la disposición legal, se establece su constitución de oficio por parte del Ministerio de Industrias, lo cual re- sultaria incongruente en el caso de los sindicatos que nacen por decisión voluntaria de la mayoria de trabajadores.

Por la misma razón, en toda empresa industrial que cumpla con los requisitos mírimos existe legalmente una Comunidad, en tanto que no en todo centro de trabajo donde pueda existir una asociación profesional, existe un Sindicato pues la mayoria puede no haberlo decidido.

\section{Distinciones con respecto a la calidad de miembro en ambas instituciones}

\subsection{Asociación voluntaria en el Sindicato.}

El principio de asociación voluntaria es consecuencia del principio de constitución voluntaria que hemos visto rige para el campo sindical.

Son miembros de un Sindicato aquellos que voluntariamente se han afiliado al mismo, siempre $y$ cuando cumplan con los requisitos estatutarios y sean aceptados como tales.

Pero, quien no manifiesta su voluntad de pertenecer al Sindicato no puede ser obligado a afiliarse, en la misma forma que la afiliación no le puede ser negada a quien cumpliendo los requisitos manifiesta su voluntad de pertenecer a la institución. Por lo demás, así está reglamentado en el Art. $4^{\circ}$ del Decreto Supremo de 3 de mayo de 1961.

De otro lado, cualquier miembro de un Sindicato puede desafiliarse del mismo. Igualmente, la asamblea de la institución o sus estatutos pueden imponer causales de separación de los miembros.

En todo caso, la afiliación o desafiliación a un sindicato no afecta ni depende de la situación de servidor que mantiene una relación de trabajo con el empleador.

Finalmente, el principio de constitución voluntaria unido al principio de asociación voluntaria determinan que para afiliarse a un Sindicato se requiera (1) pertenecer a la categoria que representa la asociación profesional (empleado u obrero); (2) no ejercer cargo de representación del empleador, salvo que los estatutos expresamente lo admitan; y (3) pertenecer a la empresa o a la actividad que los vincula con contraio de trabajo vigente y antigüedad mayor de tres meses (Art. 9o del Decreto Supremo de 3 de mayo de 1961 y Resolución Suprema de 17 de julio de 1957). 


\subsection{Asociación obligatoria en la Comunidad Industrial.}

Consecuencia de la constitución por mandato de la ley en la Comunidad Industrial, es que sus miembros lo son porque así la ley lo dispone y no porque ellos lo decidan.

El Capítulo III del Decreto Ley 18384 contiene las normas sobre miembros de la Comunidad industrial. Como norma general se establece que lo son los trabajadores estables a tiempo completo que perciben sueldo o salario y laboran real y efectivamente a tiempo completo en la empresa. $Y$ la calidad de miembro la adquiere el trabajador que cumple con esas condiciones, no desde que manifiesta su voluntad de afiliarse, como en el sindicato, sino desde que adquiere la condición de trabajador estable. Con respecto a esto último sí podría señalarse una similitud con el requisito de tres meses de antigüedad establecido en el régimen de sindicalización ya que conforme al Art. $3^{\circ}$ del Decreto Supremo 001-71-TR, que reglamenta el Decreto Ley 18471 sobre estabilidad en el empleo, se adquiere el derecho a la estabilidad, vale decir, la condición de trabajador estable, cumplido el período de prueba que según la Ley 14218 es de 3 meses.

No cabe, entonces, en la Comunidad Industrial la separación de un miembro por acuerdo de la asamblea, por sanción disciplinaria o por determinación de sus estatutos. Solamente se deja de pertenecer a la comunidad al cese o terminación de la relación de trabajo, o cuando subsistiendo la relación no tiene el trabajador las condiciones señaladas en el Art. 12\% del Decreto Ley 18384 o en la eventualidad de haber perienecido a más de una Comunidad Industrial, caso expresamente prohibido por el referido artículo.

Finalmente, los Decretos Leyes 18350 y 18384 expresan que la Comunidad Industrial agrupa a la colectividad de trabajadores, sin la distinción entre empleados y obreros que subsiste en el régimen de sindicación. Más aún, a diferencia del Sindicato, pertenecen a la comunidad también los servidores que ejercen cargos de representación del principal y aún los que tengan acciones de la empresa siempre y cuando cumplan con las condiciones del artículo $12^{\circ}$.

El propio artículo 8 del Decreto Ley 18384 corrobora esta afirmación desde que le asigna al trabajador de mayor categoría administrativa la función de convocar y presidir la asamblea de instalación de la comunidad.

\section{Diferencias con respecto a la relación de trabajo para ser miembro del Sindicato y de la Comuni- dad Industrial}

Si consideramos que sindicato y comunidad industrial tienen como común denominador agrupar y representar a una colectividad de trabajadores, conviene analizar las condiciones que deben cumplir sus integrantes para pertenecer, sea por asociación voluntaria, sea por mandato de la ley, a cada una de las citadas instituciones.

\subsection{Contrato de trabajo vigente en el Sindicato.}

Se ha visto que para constituir o afiliarse a un Sindicato se requiere, cuando menos, contrato de trabajo vigente y antigüedad mayor de tres meses (Resolución Suprema de 17 de julio de 1957). Pero como estamos tratando de sindicato de centro de trabajo, es preciso completar este requisito minimo con otras regulaciones impuestas por la legislación.

La Resolución Suprema de 17 de julio de 1957 al establecer en su Art. 1 el requisito mínimo de contrato de trabajo, añade que dichos contratos deben provenir "de los citados centros de trabajo". Por otro lado, la Resolución Ministerial de 27 de setiembre de 1957 manifiesta que el reconocimiento de los sindicatos recaerá sobre las organizaciones que agrupan trabajadores "del mismo centro de trabajo de la misma actividad o del mismo departamento", añadiendo que una unidad sindical no podrá agrupar a trabajadores de "diferentes actividades, cumplidas en compañias, empresas o entidades que realizan sus funciones comerciales o industriales con personería jurídica propia y en distintos centros de trabajo". Se complican aún más las cosas cuando el Art. 9 del Decreto Supremo de 3 de mayo de 1961 dispone que para ser miembro de un sindicato se requiere "pertenecer a la empresa o acîividad que los vincule".

Del análisis de estas normas debe concluirse que la legislación peruana sobre sindicalización permite, para los sindicatos de centro de trabajo, que pueda constituirse un sindicato en aquellos centros de trabajo que actúan con personería jurídica propia y, como consecuencia de ello, pertenecerán a dicho Sindicato únicamente los trabajadores que tengan contrato de trabajo con la persona juridica que tiene a su cargo el centro de trabajo y en cuya planilla estén registrados los fundadores del sindicato o los que pretenden afiliarse. Permite hacer esta afirmación lo dis- 
puesto en el Art. 1 del Decreto Supremo de 17 de julio de 1957 cuando establece que el visitador que revise la lista de adherente a una organización sindical requerirá al principal la presentación del libro de planillas para comprobar el requisito de mayoría exigido por la ley.

Con esto las empresas podrían legalmente dividirse en personas jurídicas distintas con objeto de restar unidad a la organización sindical o simplemente anularla en algunos casos. Aunque no haya estudios ni elementos de juicio suficientes como para comprobar que, en la realidad, se esté utilizando esta "puerta abierta" resulta criticable que la frondosidad de nuestra legislación lo permita $y$, por ello, requiere modificaciones radicales en este aspecto.

\subsection{Relación laboral vinculada a la empresa indus- trial en la comunidad industrial.}

Los decretos leyes 18350 y 18384 en lo que se refieren a comunidades industriales, rompen el criterio estricto del contrato de trabajo y su estrecha vinculación al libro de planillas.

Lo hacen desde el momento en que corresponde a la comunidad la representación del conjunto de trabajadores sin estar necesariamente vinculado a la relación de servidores que aparecen en planilla, ni sujetarse al criterio de la persona juridica que actúa como principal o empleador.

La legislación de Comunidad Industrial, en lugar del contrato laboral, ha elegido el criterio de empresa y ha sustituido al contrato por la relación laboral.

Cuando la ley dispone la constitución de la Comunidad expresa que deberán concurrir a la asamblea todos "los trabajadores estables que laboran a tiempo completo en la empresa" (Art. 8 del D.L. 18384). Repite, luego, el mismo criterio al establecer quiénes son miembros de la comunidad (Art. 12, D. L. 18384). Además, en la Cuarta Parte del Decreto Ley 18350, se encuentra una definición operativa de Empresa Industrial: "son las entidades que se dedican a la transformación de insumos materiales $\mathrm{y} / \mathrm{o}$ producción de bienes económicos". Como se ve, no hay ninguna referencia a la persona jurídica sino expresa consignación de unos términos más amplios y abstractos: empresa o entidad. Dentro de estos términos, una comunidad industrial puede legalmente reunir a trabajadores de distintas personas jurídicas, registrados en diferentes libros de planillas, siempre que estas per- sonas jurídicas diferentes constituyan una sola entidad dedicada a la producción industrial y sus actividades derivadas.

Pero no sólo por interpretación de las normas se concluye que la Comunidad reúne a servidores de distintas personas jurídicas. El Decreto Ley 18384, expresamente, en su Art. 52, dispone que "los trabajadores de empresas de servicios que laboren en forma estable en una empresa industrial serán considerados miembros de la Comunidad Industrial de esta empresa'. Esto demuestra que servidores de persona jurídica distinta de la que ejerce la actividad industrial (como es la empresa de servicios), registrados en otra planilla de pagos, son miembros de la comunidad industrial si laboran en forma estable en la empresa.

La legislación de Comunidad Industrial al dejar de lado el criterio de la persona juridica y el contrato de trabajo, busca un criterio más cercano a la realidad.

En general, la ley determina que el trabajador - prescindiendo de quién es el principal o del libro de planillas que firma-, por el hecho de estar laborando en forma real y efectiva y de manera estable en una entidad industrial, es miembro de la Comunidad que se constituye en dicha entidad. Esto es realista y evita que mediante ficticias constituciones de personas jurídicas distintas 0 traslados en los libros de planillas se debilite la unidad de los trabajadores de una entidad industrial. Por lo demás, basta con que un trabajador acredite laborar real, efectiva $y$ establemente en la entidad industrial, aún cuando pertenezca a una empresa de servicios, para que tenga la facultad de integrarse a la Comunidad.

\section{OBJETIVOS:}

\subsection{Objetivos del sindicato.}

Basta para este estudio referirse a la finalidad inmediata de la asociación profesional: el mejoramiento económico del trabajador. Por el momento el fin mediato o político del Sindicato será dejado de lado no porque tenga menor importancia, sino porque este aspecto requiere de un estudio diferente que escapa a los alcances del presente trabajo.

El Art. 1 del Decreto Supremo de 3 de mayo de 1961 expresa en términos generales la finalidad del Sindicato: los trabajadores tienen derecho a asociarse li- 
bremente en sindicatos "para su mejoramiento económico, social y cultural y la defensa de sus intereses comunes". En este dispositivo se reflejan los dos propósitos fundamentales del Sindicato: la defensa de intereses comunes a la clase trabajadora y la lucha por obtener mejores condiciones salariales y de trabajo. El Sindicato es la única forma de asociación que por esencia y por disposición legal tiene estas finalidades como propias.

Otras normas legales refuerzan los objetivos precisos y exclusivos del sindicato e implementan los procedimientos a utilizarse para cumplirlos a cabalidad.

\subsubsection{Defensa de intereses comunes}

El Decreto Supremo 006-72-TR regula el procedimiento de denuncia para la solución de conflictos de aplicación. Este procedimiento aplicable para defender al trabajador individualmente o colectivamente ante el incumplimiento o violación de las disposiciones legales y/o convencionales de trabajo, cuando el vinculo laboral está vigente, también puede utilizarse para exigir la reposición en el trabajo por despedida injustificada o la reincorporación al empleo invocando un derecho preferencial. Este Decreto consagra en el Art. $17^{\circ}$, incisos b) y f), la facultad de los sindicatos de presentar denuncias ante la Autoridad de Trabajo. Según lo expresado con referencia al requisito de mayoría y a la representatividad de la organización sindical, éstas pueden presentar denuncias por violación o incumplimiento de normas que afecten a la colectividad de trabajadores o a un servidor individualmente, esté o no afiliado, a condición de que pertenezca a la misma categoria del sindicato denunciante.

En caso de que un trabajador sea injustificadamente despedido, puede el Sindicato de su categoría formular la denuncia ante la autoridad del trabajo solicitando la reposición del despedido según los términos contenidos en el Decreto Supremo 001-71-TR. En realidad, la despedida injustificada constituye una violación de las disposiciones sobre estabilidad laboral contenidas en el Decreto Ley 18471.

Si se tratase de una solicitud para suspender total o parcial en forma temporal de las actividades del empleador, o para reducir el personal, turnos, horas y dias de trabajo $\mathrm{y} / \mathrm{o}$ para despedir totalmente al personal por liquidación de la empresa, el Sindicato también tiene la representación de los trabajadores afectados en las Juntas de Conciliación que necesa- riamente deberá convocar la Autoridad de Trabajo, según lo establecido por el Art. 50, inciso b, del Decreto Ley 18471. En el supuesto de que se acepte la solicitud de reducción de personal y el empleador decidiera contraiar a nuevos servidores, el Art. $7^{\circ}$ del Decreto Ley 18471 le otorga al trabajador despedido el derecho preferencial de reingresar al centro de trabajo si por su categoría y calificación puede ocupar los puestos ofrecidos. Aún cuando para este caso específico la ley no hace expresa referencia a la participación del Sindicato, debe entenderse que la organización sindical también está facultada para representar al trabajador despedido. Este sería el único caso en que la asociación profesional actúa en representación de trabajadores cuyo contrato de trabajo no se encuentra vigente.

El sindicato tiene también la facultad de intervenir en cualquier diligencia de inspección que se lleve a cabo según los postulados del Decreto Supremo 003-71-TR, en cuyo Art. $10^{\circ}$ se obliga al Inspector-Visitador a llamar a los dirigentes de la organización sindical del centro de trabajo.

\subsubsection{Mejoramiento económico de los trabajadores.}

La otra labor encomendada a los sindicatos es la lucha por la obtención de mejoras salariales o de condiciones de trabajo. Para cumplir con esta misión, la ley ha establecido el procedimiento de negociación colectiva que se encuentra regulado por el Decreto Supremo 006-72-TR de 29 de noviembre de 1971.

La facultad de iniciar el procedimiento de negociación colectiva mediante la presentación del pliego de reclamaciones es exclusiva del Sindicato donde exista. Solamente a falta de organización sindical, representantes de la mayoría de trabajadores podrán presentar y tramitar un pliego de reclamaciones. Así lo establecen claramente los Arts. $60^{\circ}$ y $14{ }^{\circ}$ del Decreto Supremo 006-71-TR.

Es necesario, recalcar que cuando un sindicato presenta un pliego de reclamaciones, to hace en representación de todos los trabajadores de la categoría a que representa, estén o no sindicalizados. Además, los acuerdos a que llegue la organización sindical en trato directo o en Junta de Conciliación o las resoluciones de la Autoridad de Trabajo que pongan fin al procedimiento de negociación colectiva, se aplican y benefician a los trabajadores afiliados al Sindicato $y$ a los demás de la misma categoria que no se en- 
cuentren afiliados. Esto es consecuencia de la representación colectiva que ejerce el Sindicato y del sistema de unidad sindical a que se acoge la legislación peruana. Por lo demás estos principios han sido recogidos con exactitud por el Art. 43 del Decreto Supremo 006-71-TR.

\subsubsection{Mejoramiento social y cultural y otros derechos específicos.}

Luego de analizar los objetivos fundamentales de los sindicatos en el cumplimiento de su fin inmediato, que es el que nos ocupa, conviene decir unas palabras referidas a otros objetivos relacionados con los primordiales y cuyo cumplimiento también debe ser preocupación de los sindicatos.

El Art. $1^{\circ}$ del Decreto Supremo de 5 de mayo de 1961 se refiere expresamente al mejoramiento social y cultural de los trabajadores como tarea de los sindicatos. Estos propósitos no están expresamente reglamentados por dispositivos legales y para cumplirlos los sindicatos pueden llevar adelante cualquier tipo de acciones siempre y cuando éstas no signifiquen la dedicación institucional a asuntos políticos, religiosos o de índole económica con propósito de lucro, lo cual sí queda expresamente prohibido por el Art. $6^{\circ}$ del Decreto últimamente citado.

Como veremos más adelante, la ley ha asignado estos mismos objetivos a las comunidades industriales y en este campo en que las disposiciones han coincidido, ambas instituciones están llamadas a actuar en conjunto.

Finalmente, los sindicatos de empresas periodisticas tienen, además de las facultades señaladas para cumplir sus objetivos, un derecho específico que consiste en contar con una columna de opinión en la cual el sindicato o los trabajadores de la empresa periodística pueden expresar libremente sus puntos de vista (art. $4 \%$ del D.L. 18139).

\subsection{Objetivos de la comunidad industrial:}

La legislación de Comunidades Laborales constituye el primer intento realizado en el pais de modificar el esquema general de la empresa capitalista al otorgar privilegios especiales al conjunto de trabajadores que laboran en ella. Estas disposiciones - que de ninguna manera pueden considerarse como definitivas- deben interpretarse como un sistema que en forma transitoria busca que el conjunto de trabajadores tenga efectiva participación en la totalidad de la em- presa capitalista cuya progresiva modificación permite. No se puede pensar, ante el anuncio de la creación de un sector prioritario de propiedad social, que la comunidad ejemplifique el modelo más avanzado de organización empresarial que no entrega la administración integral de los medios de producción en manos de los trabajadores.

La finalidad buscada por la Comunidad es la participación del conjunto de trabajadores que están vinculados a la actividad que realiza la empresa. En tanto que hace posible la progresiva participación del trabajador, se puede decir que la comunidad "abre las puertas" a la reforma de la empresa capitalista tradicional.

Los objetivos señalados por la ley para la comunidad industrial son: "(a) el fortalecimiento de la empresa industrial mediante la acción unitaria de los trabajadores en la gestión, en el proceso productivo, en la propiedad empresarial y en la reinversión, así como por medio del estímulo a formas constructivas de interrelación entre el capital y el trabajo; (b) la unificación de la acción de los trabajadores en la gestión de la empresa industrial para cautelar sus derechos e intereses que como propietarios les acuerda el Decreto-Ley No 18350; (c) la administración de los bienes que reciba en beneficio de los trabajadores, y (d) la promoción del desarrollo social, cultural, profesional y técnico de los trabajadores" (Art. $3^{\text {o }}$ del Decreto Ley 18384).

No obstante la detallada exposición de objetivos de la ley, si se considera la búsqueda de participación del conjunto de trabajadores en la empresa industrial, se puede establecer que los objetivos fundamentales a conseguir por la comunidad Industrial son: (a) participación en los beneficios generados, (b) participación en la propiedad y (c) participación en la gestión de la empresa.

\subsubsection{Participación en los beneficios.}

Mediante la deducción de un porcentaje anual fijo de los beneficios producidos (técnicamente denominados Renta Neta) la ley faculta a la comunidad a participar en la riqueza generada (Arts. $21^{\circ}$ y $24^{\circ}$ del Decreto Ley 18350 y Art. $16^{\circ}$, incisos a y b del Decreto Ley 18384).

Una porción de la participación en los beneficios (el $10 \%$ de la Renta Neta), está destinada a ser distribuida en forma liquida entre todos los trabajadores 
de la empresa, sin que - sólo en el caso de la industria- la Comunidad tenga intervención alguna (Art. 21ㅇ del Decreto Ley 18350 y Decreto Supremo 003-71-TR de 1971).

Otra porción de la participación en los beneficios (el $15 \%$ de la Renta Neta) se utiliza para adquirir progresivamente parte del capital hasta llegar al límite actualmente señalado del $50 \%$ del capital social (Art. 16\%, incisos a y b del Decreto Ley 18384).

Asimismo, la Comunidad al convertirse en accionista, participa como tal de los beneficios mediante la recepción de dividendos, utilidades o intereses de las acciones, participaciones o bonos adquiridos a su nombre (Art. 19\%, inciso a, parágrafo (1), del Decreto Ley 18384).

\subsubsection{Participación en la propiedad.}

Mediante la utilización del $15 \%$ de la renta neta, la Comunidad Industrial progresivamente va adquiriendo, en forma obligatoria, parte del capital de la empresa.

El Art. $24^{\circ}$ del Decreto Ley 18350 y el Art. 16, incisos a) y b) del Decreto Ley 18384 regulan el sistama de participación obligatoria en la propiedad de la empresa.

Dos fórmulas pueden ser utilizadas: (a) reinversión del porcentaje correspondiente a la Comunidad y emisión de nuevas acciones siempre que la Empresa tenga aprobado un plan de reinversión por el Ministerio de Industria y Comercio (Art. $16^{\circ}$ inciso a) del Decreto Ley 18384 y artículo $12^{\circ}$ del D.L. 19262); (b) compra de acciones de accionistas anteriormente emitidas cuando la empresa carece de plan de reinversión aprobado.

De utilizarse la fórmula (a) se valorizan las acciones al valor nominal (art. $2^{\circ}$ del D.L. 19419). Si se trata de la fórmula (b) se valorizan según acuerdo entre las partes; a falta de acuerdo se toma la cotización en bolsa; y, a falta de ambos, se calcula la diferencia entre los activos y los pasivos, sobre el número de acciones constitutivas del capital pagado de la empresa (D.L. 19419).

Existen también disposiciones que regulan la participación voluntaria de la Comunidad Industrial en la propiedad de la empresa.

El Decreto-Ley 19340 ha establecido los procedimientos a utilizarse cuando la Comunidad tiene un de- recho preferencial de compra de acciones (en caso de cualquier aumento de capital distinto a la reinversión del $15 \%$ de la Renta Neta correspondiente a la comunidad, si ésta es accionista, conforme a los artículos 216 y 109 , inc. $4 \%$ ), de la Ley de Sociedades Mercantiles; 0 tratándose de una empresa periodística según lo dispuesto por el artículo único del D.L. 19270) o si existe acuerdo para que la Comunidad adquiera acciones de la empresa (supuesto que puede presentarse con frecuencia para la conversión de empresas extranjeras y nacionales según el Decreto Ley 18999). Con este fin se ha establecido un sistema de financiación mediante préstamos provenientes de la empresa o de la Banca Estatal, con el cual la Comunidad Industrial puede incrementar su participación en la propiedad de la empresa.

Es menester destacar que la participación en la propiedad de la empresa se otorga solamente para las empresas sujetas al régimen de la actividad priva$\mathrm{da}$, puesto que las empresas industriales dedicadas a la industria básica, así como las empresas con participación del Estado dedicadas a la explotación de industrias de primera prioridad declaradas por Decreto Supremo como Estratégicas para el Desarrollo Nacional y con niveles de inversión y tecnología que los justifiquen destinarán, el $15 \%$ de la renta neta a la adquisición de bonos de la misma empresa o, a falta de éstos, aportarán dicho porcentaje en valores de la Corporación Financiera de Desarrollo (COFIDE) (Art. 26. del Decreto Ley 18350, según la modificación establecida por el Decreto Ley 19262).

\subsubsection{Participación en la gestión}

Quizá el derecho más importante otorgado por la legislación de Comunidades Laborales sea el de participar en el órgano director de la empresa, sobre todo si se considera que este derecho se hace efectivo desde el momento en que se instala la Comunidad y permanece aún en los casos en que el ejercicio económico arroje pérdida, o cuando por la naturaleza de la empresa la Comunidad no participe en la propiedad de la misma.

El Art. 28 del Decreto Ley 18350 obliga a que el directorio de toda empresa industrial tenga participación del conjunto de trabajadores mediante un representante, de la Comunidad, cuando menos, elegido entre los miembros del Consejo, según mandato del Art. 33, inciso d) del Decreto Ley 18384. 
Conforme vaya la comunidad incrementando su participación en la propiedad de la empresa, aumentará su representación en el directorio y por ende su participación en la gestión.

En los casos en que la comunidad por ley no participe en la propiedad de la empresa (industria básica o estratégica) tendrá derecho a designar a dos representantes al órgano director.

Los deberes y derechos relativos al representante de la comunidad en el directorio (comunmente denominado director-comunero) se rigen por las normas que sobre directores contiene la Ley de Sociedades Mercantiles. Sin embargo, el director comunero está premunido del derecho especial de revisar todos los libros de contabilidad y documentos que inciden en la formación de la renta neta de la empresa, pudiendo efectuar dicha revisión asesorado por cualquier miembro de la comunidad y/o cualquier especialista contratado para dichos fines (art. $40^{\circ}$ del D.L. 18350, según el agregado establecido por el D.L. 19262).

\subsubsection{Promoción del desarrollo social, cultural, profe- sional y técnico de los trabajadores y otros obje- tivos de la comunidad.}

Poco hay legislado en este campo, pero está específicamente consignado en el inciso d) del Art. $3^{\circ}$ del Decreto Ley 18384 que la comunidad industrial tiene como objetivo promover el desarrollo social, cultural, profesional y técnico de los trabajadores y en este punto se encuentra una coincidencia con la legislación sindical como se ha señalado anteriormente. Es verdad que resulta prácticamente imposible legislar con detalle este campo que corresponde a ambas instituciones por ser las dos representativas de la colectividad de trabajadores de una empresa. También es cierto que las leyes no pueden sustituir la voluntad de los trabajadores para reglamentar la forma más adecuada de cumplir con el mejoramiento social, cultural, profesional y técnico de los servidores, ya que únicamente ellos podrán decidir su propia estrategia en este campo.

Finalmente, por tener las comunidades industriales la posib:lidad de gozar de considerables intereses patrimoniales, la ley ha especificado como objetivo de las mismas la administración de los bienes que reciban o adquieran (Art. 3\%, inciso c), del Decreto Ley 18384), lo cual también corresponde al Sindicato en caso de tener en su poder bienes, en tanto que es una per- sona jurídica que se rige supletoriamente por las normas del Código Civil (art. 43).

\subsubsection{Representatividad y procedimientos de la comu- nidad para cumplir sus objetivos.}

La legislación de comunidades industriales, mucho más reciente que la legislación sindical, no es tan específica en señalar procedimientos para que las comunidades exijan el cumplimiento de las normas legales que las regulan. No obstante, ya se percibe la urgente necesidad de crear organismos de competencia exclusiva para la solución de los inevitables conflictos que surjan con motivo de la aplicasión de la legislación de comunidades y de señalar procedimientos determinados para estos efectos.

Sin embargo, la ley no ha dejado de consagrar que las Comunidades Industriales tienen la representación del conjunto de trabajadores ante las autoridades judiciales, administrativas y municipales $y$ ante entidades públicas y privadas (Art. 33\%, inciso h), del Decreto Ley 18384).

Solamente ha sido específica la ley al otorgar al representante de la comunidad el derecho especial de revisar los libros y cuentas de la empresa, según lo expuesto en el punto referente a la participación en la gestión (Art. 40 del Decreto Ley 18350, según el agregado establecido por el D.L. 19262).

\section{Relaciones entre la Comunidad Industrial y el Sindicato}

La detallada distinción anteriormente expuesta nos permite afirmar que Sindicato y Comunidad Industrial son instituciones perfectamente diferenclables por su origen, composición y objetivos. No podrán, en ningún caso, confundirse ni será posible pensar que una de ellas va a sustituir a la otra puesto que cada una tiene sus propias funciones que cumplir y sus modos particulares de actuar en beneficio de los trabajadores. Esto, sin embargo, no significa que no sea posible, y en algunos casos necesario, que Comuridad Industrial y Sindicato se vinculen estrechamente a fin de coordinar actividades y complementar esfuerzos.

\subsection{La Comunidad no sustituye al Sindicato}

Debe destacarse que no existe ninguna razón para pensar que la Comunidad Industrial ha sustituido - va a sustituir a los Sindicatos. Por el contrario, al prohibir el artículo 14, inciso a) del D.L. 18484 que un Dirigente Sindical integre al mismo tiempo el Con- 
sejo de la Comunidad Industrial, la misma legislación está determinando la distinción entre ambas organizaciones y está reconociendo que por tener objetivos distintos y medios de acción diferentes es necesario que las mismas personas no acaparen la dirigencia de ambas.

Por otro lado, con posierioridad a la creación de la Comunidad Industrial se han dictado los decretos supremos 006-71-TR y 006-72-TR que reglamentan los procedimientos de negociación colectiva y denuncias, e los cuales - como se ha visto anteriormente- los sindicatos cumplen un rol preponderante. Si el propósito del legislador fuese sustituir a los sindicatos por las comunidades, se les hubiese dado a éstas la facultad de participar ei dichos procedimientos. Más aún, la jurisprudencia administrativa ha dejado claramente establecido que una Comunidad Industrial no tiene personería en los procedimientos laborales y no puede sustituir en estos casos a un Sindicato (Véase el auto de fecha 20 de diciembre de 1971, publicado en Asesoria Legal, № 1, p. 11, en el cual, por este motivo, se rechaza un pliego de reclamaciones presentado por una Comunidad Industrial). De igual forma, la Oficina de Comunidades Laborales del Ministerio de Industria y Comercio ha opinado en muchos casos que un Sindicato no debe sustituir a la Comunidad en aquellos puntos que sean de competencia de esta última.

En todo caso, la existencia del sindicato y su permanente lucha en bien de los asalariados está garantizada por las leyes vigentes. Tal vez en el futuro, cuando la Comunidad tenga considerable participación en la propiedad de la empresa se haga necesaria una reorientación de los sindicatos en función de la situación del momento. Mientras tanto, el rol del sindicato no ha variado sustancialmente.

\subsection{Coordinación de esfuerzos.}

Como se ha determinado, tanto el Sindicato como la Comunidad agrupan a trabajadores y tienen objetivos específicos en beneficio de ellos. Esto trae como consecuencia que en algunos casos los intereses de ambas organizaciones coincidan o se relacionen estrechamente.

Es un hecho que al crearse las comunidades industriales se presentó un momento de confusión y se aprovechó para confundir a la clase trabajadora y la fuerza y unidad que ha alcanzado en el país.
No obstante, la experiencia ha demostrado lo contrario. En algunos casos, especialmente en empresas con poco personal, el nacimiento de la Comunidad permitió un grado de organización de los trabajadores que, inmediatamente, vieron la necesidad de constituir su propio Sindicato para conseguir reivindicaciones específicamente laborales, y lo hiceron. En otros casos, la Comunidad —que agrupa a obreros y empleados- ha proporcionado la ocasión para que ambas categorias de trabajadores intercambien ideas y encuentren coincidencias en sus reivindicaciones, to cual ha determinado la unidad de sindicatos de obreros y empleados o la búsqueda de una estrategia común entre ambas clases de asociaciones profesionales.

De otro lado, la experiencia también demuestra que para el mejor cumplimiento de los objetivos de la Comunidad se hace imprescindible contar con el apoyo del Sindicato, especialmente si se tiene en cuenta que el destino de la Comunidad Industrial depende, en gran medida, de la fuerza de las Comunidades y del movimiento comunero para exigir el cumplimiento de la ley y obtener ciertas modificaciones que la perfeccionen. Un primer contacto con la realidad demostrará que las Comunidades que major han exigido el cumplimiento de sus derechos, son aquellas que cuentan con Sindicatos poderosos que las respaldan. Esto no significa que el Sindicato haya intervenido directamente en los conflictos de la Comunidad, ni que la haya sustituido en sus reclamaciones. Esto simplemente demuestra que las comunidades que coordinan sus actividades con los sindicatos son las que cuentan con mejor posición para exigir el respeło y reconocimiento de sus derechos. Recordemos, por lo demás, la larga experiencia de los sindicatos en lo que se refiere a exigir el cumplimiento de los derechos de los trabajadores.

Algunos pocos ejemplos permiten afirmar que, en el futuro, las Comunidades Industriales tendrán múltiples oportunidades de establecer estrategias comunes con los sindicatos, actuando algunas veces como intermediarios entre el Sindicato y la Empresa, o apoyando, en otras, enérgicamente al Sindicato a fin de obtener el beneficio de los trabajadores.

Por último, un campo propicio para que la Comunidad $y$ el Sindicato actúen coordinadamente, es aquel en que estas instituciones buscan proporcionar servicios para sus miembros, campo en el que, además, la legislación coincide. 
Ya hemos dicho que tanto el D.S. 009 de 3 de mayo de 1961 como el D.L. 18384, señalan como objetivos de la Comunidad y del Sindicato el desarrollo o mejoramiento social, cultural, profesional y técnico de los trabajadores. También hemos advertido que la legislación se limita a puntualizar estos objetivos sin entrar en mayores detalles, to cual es comprensible pues su cumplimiento depende de la organización de actividades que lo permitan y del interés que demuestren los dirigentes de ambas instituciones.

Resulta obvio que la consecución de estos objetivos coincidentes, hace necesaria la coordinación entre el
Sindicato y la Comunidad quienes en este aspecto están contribuyendo a la realización integral del trabajador. Tal vez valga la pena señalar que es probable que las Comunidades cuenten con mayores recursos para cumplir con estos objetivos por que la ley les permite contar con fuertes cantidades de dinero $y$, específicamente, el punto 3 ), del inciso $\mathrm{c}$ ), del artículo 20 del D.L. 18384, dispone que un máximo del $20 \%$ del ingreso anual del Fondo General de la Comunidad se utilizará para sufragar los gastos que demande el desarrollo social, cultural, profesional y técnico de sus miembros. 